\title{
Grape Quality Parameters in Western Carpathian Region under Changing Climatic Conditions as Influenced by Drought
}

\author{
Slavko Bernáth ${ }^{1 *}$, Bernard Šiška², Oleg Paulen'1, Veronika \\ Zuzulová2, Eduard Pintér', Matej Žilinský2 ${ }^{2}$ František Tóth ${ }^{3}$ \\ 1 Department of Fruit Production, Viticulture and Enology, Slovak University of Agriculture in Nitra, A. Hlinku 2, \\ 94976, Nitra, Slovakia \\ 2 Department of Environmental Management, Slovak University of Agriculture in Nitra, A. Hlinku 2, 94976, \\ Nitra, Slovakia \\ ${ }^{3}$ Gemerprodukt Valice, Okružná 3771/116, 97901 Rimavská Sobota, Slovakia \\ * Corresponding author's e-mail: Slavko.Bernath@uniag.sk
}

\begin{abstract}
Western Carpathians are historically the northern range traditional grapevine growing areas since the Middle Ages. The mean anual temperature has increased by about $1.1^{\circ} \mathrm{C}$ during the last century in Slovakia. Elevated temperature impacted the growing conditions of grapevine. Together with the increased temperatures, higher frequency of drought periods and parameters are evident. Traditional grape producing areas are facing new challenges. Except for the accelerated grapevine phenology, pathogene infection pressure and occurence of pests including new ones, as well as the quality of grapes influencing wine quality, are changing. In order to evaluate the drought impact on the quality parameters of grapes the locality of the Cultivar Testing Station in Dolné Plachtince which belongs to the Central Slovakian grape producing region was chosen. Interanual variability of the drought impact on the grape quality was evaluated according to Palmer drought severity index (PDSI). The 1990-2014 period was used as a basis for evaluation. The period with the phenological phase crucial for the grape quality formation was determined. Two groups of cultivars with different ripening periods were selected. Pinot Gris, Muscat Ottonel Weiss, Müller Thurgau represented the early ripening cultivars (OIV earliness code 4 and 5), whereas Grüner Veltliner, Riesling, Welschriesling represented the late ripening cultivars (OIV code 8 and 9) were used. The cumulative values of PDSI for the crucial periods were calculated. The PDSI values as well as the sugar and acid contents were correlated to find the strength of relation between them. Short drought periods did not influence the grape quality significantly, while long drought periods caused a decrease of the acid content and an increase of the sugar content. Though the tendency was clear, the correlation level was mostly low. The most sensitive period in this sense was July-September; however, it was influenced by the ripening term of individual cultivars. The results suggest the necessity of a thorough approach to cultivar selection, taking into account its vitality and ability to preserve a satisfactory acid content in grapes by the harvest date.
\end{abstract}

Keywords: drought, grape, acid content, sugar content.

\section{INTRODUCTION}

Grapevine (Vitis vinifera L.) has been grown in Slovakia for thousands of years [Poláček and Poláček, 2009]; therefore, it is regarded as a traditional crop in the warmer regions of the country where grapevine is grown on lowlands and mainly on adjacent slopes. The Western Carpathian region is the northern range of commercial grapevine production in the eastern part of the Central Europe. Climate factors such as solar radiation and temperature are limiting the extension of the vine growing areas in the region, and weather conditions in individual years influence the quality of grape and wine remarkably.

Central Europe, similarly to other regions of the world, is facing the phenomena related to the climate change. The globally averaged combined 
land and ocean surface temperature show a warming of $0.85(0.65 \text { to } 1.06)^{\circ} \mathrm{C}$, over the period 1880 to 2012 [IPCC, 2013]. During the $20^{\text {th }}$ century, the average temperature increase in Europe $+0.95^{\circ} \mathrm{C}$ [EEA, 2004] was higher than the global mean increase. Mean annual temperature increased by $1.1^{\circ} \mathrm{C}$ during the last century in Slovakia [Balajka et al., 2005]. An increase by $1.6^{\circ} \mathrm{C}$ and annual precipitation decrease by $24 \mathrm{~mm}$ was registered in Slovakia the period of $1881-2007$. An analysis of the growing period in Slovakia in 1881-1987 showed that higher temperature average is usually connected with lower precipitation and vice versa. However, this correlation is ambiguous in the recent years [Faško et al., 2008]. In 19912014 period, the average annual temperature increased by $0.9-1.1^{\circ} \mathrm{C}$ compared to its average value in the 1960-1990 period on the Slovakia's territory [Labudová et al., 2015]. An increase of the global mean surface temperatures for 20812100 relative to $1986-2005$ is projected to likely be in the ranges derived from the concentrationdriven CMIP5 model simulations (RCP4.5), that is, $1.1^{\circ} \mathrm{C}$ to $2.6^{\circ} \mathrm{C}$ [IPPC, 2013].

An increased duration of the growing period affects also the potential for the drought occurrence [Šiška and Takáč, 2009]. An increase of temperature results in higher evapotranspiration, which, together with lower precipitation in some periods, intensifies the drought manifestation. This is evident mainly in the lowland regions at the Slovakia's territory. Several quite severe droughts occurred in Europe since beginning of $21^{\text {st }}$ century, three of them - in 2003, 2012 and 2015 also hit the territory of Slovakia. The summer droughts prevailing in recent years were beginning in late May to June and peaking in July - August [Fendeková et al., 2018]. Water and temperature, as indispensable environmental factors for plants, influence different processes within them; therefore, the change of climatic conditions induces the changing appearance of agricultural crops - yields, quality of agricultural products, pest and disease pressure etc. Climate influences the grape yield and quality through meeting the temperature requirements, radiation intensities/duration, and water availability during the grapevine growing season [Magalhães, 2008; Makra et al., 2009].

The combined effect of drought with periods of high air temperature and high evaporation during the grapevine growing season could have a negative effect not only on the grape productivity but also on its berries and wine quality when environmental conditions are limiting [Chaves et al.,2007; Costa et al., 2007; Escalona et al., 1999].

A major effect of the temperature increase is an advance in the vegetative and reproductive cycles of the grapevine. The subsequent phenological stages (bud break, flowering, veraison, ripeness) are reached earlier [Parker et al., 2011]. For some European viticultural regions, in Italy, Germany, and France, studies already reported shortenings of the growing season and earlier phenological events [Bock et al., 2011; Chuine et al., 2004; Dalla Marta, 2010; Daux et al., 2012]. As a result of the acceleration of the phenological processes, grapes ripen under warmer conditions, not only because of the increase in temperatures due to global warming, but also because ripening takes place earlier in the season with naturally higher temeratures. The advances in maturation dates of approximately 4 to 8 days per decade have been detected in the major wine-growing regions of Australia, France and Germany [Jones et al., 2005]. However, the duration of each phenological stage differs according to the grapevine variety, which is generally tied to the thermal conditions of each region [Mandelli et al., 2005].

A positive correlation between the warm weather patterns and acceleration of grape harvest date over long historical period (several hundred years) was documented in the Czech Lands. Additionally, a significant correlation between dry years and good wine quality was reported [Možný et al., 2016]. Grape vine has to be grown under environmental stress. This environmental stress is most frequently water deficit, but might as well correspond to the limited nitrogen uptake. Environmental stress reduces yield, but the produced wine quality and wine typicity linked to specific environmental conditions generate higher selling prices. The wines produced under these conditions are called "terroir wines" [Van Leeuwen et al., 2007].

The composition of grape berry changes continuously during its development and ripening, and the associated metabolic pathways are under genetic control. However, the environmental factors and cultural practices, and their interaction with the cultivar, can alter the extent of these changes. Any factor altering the vine growth and/or physiology impacts the fruit composition [Keller, 2010]. Moderate dryness at the stage of grape berry maturation enhances the quality. The grapes in hot and dry years have low sugar, acid 
and colour content [Storchi et al., 2005]. Moderately restricted water supply improves the quality of red wines by causing the grapes to achieve optimal sugar levels. When the water supply is not restricted at all, the grape sugar levels are lower due to competition for carbon between berry ripening and shoot growth and increased berry size. When the water deficit is severe, the grape sugar content is depressed due to the limited photosynthesis [Van Leeuwen et al., 2009]. The early water deficit during the berry development is more effective than the late water deficit in reduction of the berry growth, leading to more concentrated content of berries in terms of sugars and anthocyanins (blue grapes). The late water deficit impairs the berry sugar accumulation due to the detrimental effect of water stress on leaf photosynthesis [Intrigliolo et al., 2012].

\section{MATERIAL A METHODS}

The locality of the Cultivar Testing Station in Dolné Plachtince (N48 ${ }^{\circ} 12.327^{\circ}$ E19 $\left.{ }^{\circ} 19.064^{\circ}\right)$ which belongs to the Central Slovakian grape producing region, district of Modrý Kameň, was chosen for the evaluation of the drought impact on the quality parameters of grapes. The Station is specialised in the testing of fruit crops and grapevine. The site is located in the southern part of the Krupinská planina, exposed to South-West with $5-10^{\circ}$ inclination, at the altitude of $228 \mathrm{~m}$ a.s.l. Soil is loam clay illimerisated brown soil, pH 6.2. Mean annual temperature (1960-1990 reference period) is $9.1^{\circ} \mathrm{C}$, mean temperature of growing period is $16.0^{\circ} \mathrm{C}$, annual precipitation $648 \mathrm{~mm}$, growing period precipitation $362 \mathrm{~mm}$, mean annual sunshine duration is 1983 hours, mean sunshine duration within growing period equals 1500 hours. The data were obtained from the experimental vineyard with cultivar collection planted in $3.0 \times 1.2 \mathrm{~m}$ spacing, trained in the Rhein-Hessen form.

Two groups of cultivars with different ripening periods were selected as model cultivars. Pinot Gris, Muscat Ottonel Weiss, Müller Thurgau represented the early ripening cultivars (OIV earliness code 4 and 5), while Grüner Veltliner, Riesling, Welschriesling represented the late ripening cultivars (OIV code 8 and 9). The phenological data used for evaluation were end of blossom (BBCH 69), and berry ripe, harvest (BBCH 89). The data were collected in the 1990-2014 period.
The meteorological data of the same period were obtained from the meteorological station in Dolné Plachtince. For the interpretation of drought, the Palmer drought severity index (PDSI) based on a supply-and-demand model of soil moisture formulated by Palmer [Palmer, 1965] was used. The values of PDSI were calculated on a monthly basis. In order to summarize the drought occurence and severity for a subsequent evaluation of its impact on the sugar and acid content in grapes, the monthly values of PDSI were summed up for the periods from the end of blossom to the grapes harvest of the observed cultivars in individual years. The strength of relationship between the drought and sugar content, as well as the drought and acid content were determined with the use of linear correlation analysis.

\section{RESULTS AND DISCUSSION}

Within the evaluated period, the years with water deficit during the period of grape berry development and ripening were prevailing. A similar situation has also been experienced in other European countries. For example, dry periods and drought in Summer was the most often reported among the phenomena related to the climate change perceived by grapevine growers in France, Italy, and Germany, followed by higher temperatures [Bataglini et al., 2009] In all the observed cultivars in our experiment, a negative correlation between the value of PDSI and the sugar content was found (Fig.1 a-f) which means that in the years with drought during the berry development and ripening, the sugar content of berries tended to be higher than in the years with humid summer. In the study concerning the grape quality as influenced by different irrigation regimes in Sardinia, full irrigation resulted in significantly lower soluble solid content compared to the deficit irrigation treatments [Oliveira et al., 2013]. Similar findings were reported from the observations in the South Tyrolean region [Wenter et al., 2018]. Some authors [Santo et al, 2007; Romero et al., 2012; Edwards and Clingeleffer, 2013; Vaz et al., 2016], however, report that concerning the soluble solids accumulation in berries affected by water shortages, the results are not consistent and vary greatly with the intensity of the stresses and the cultivar. The effect of water deficit stress on the berry sugar content is yield-dependent, for low yields, vine water deficit enhances the berry 

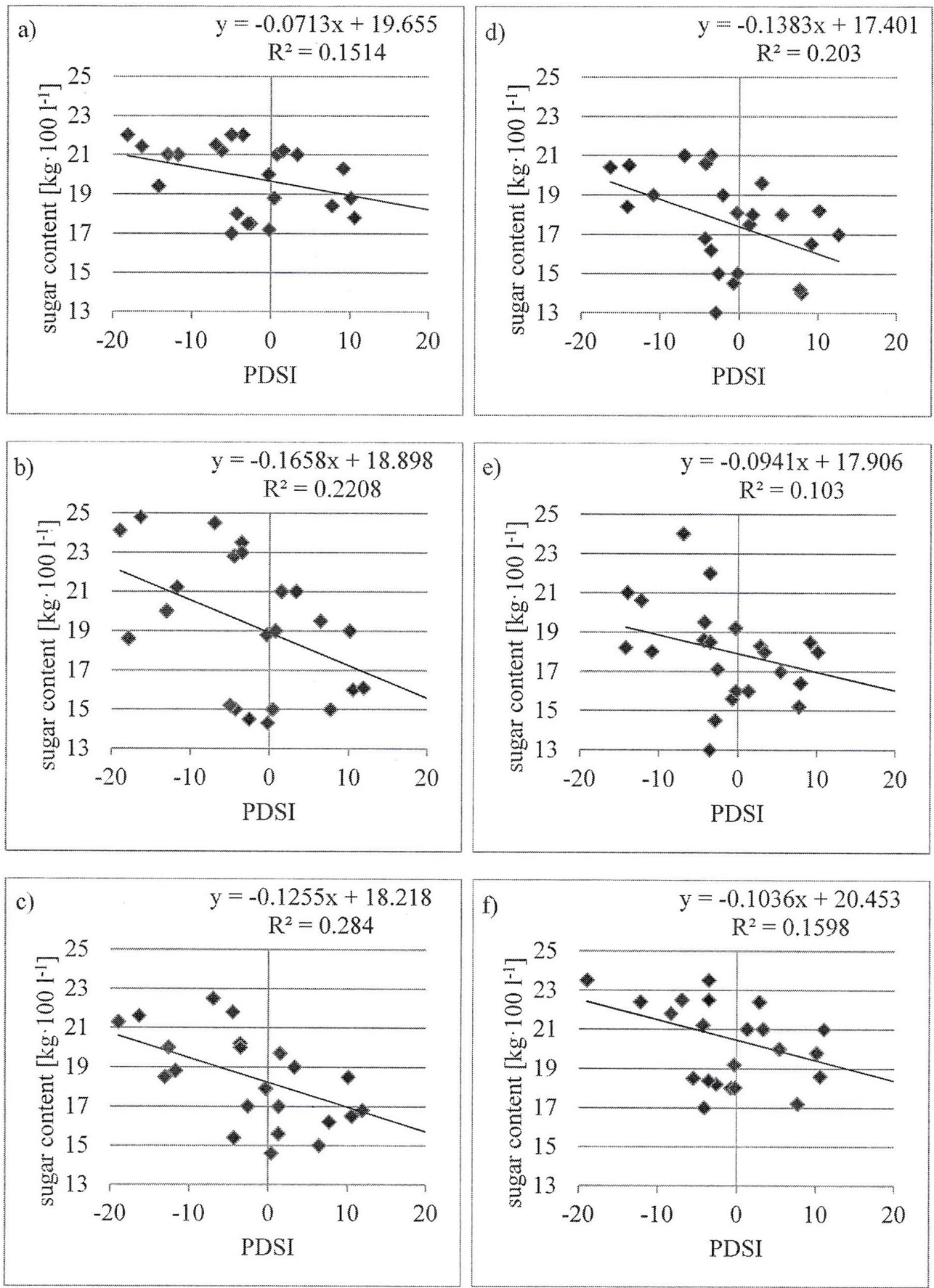

Figure 1. Correlation between PDSI in the period of grape berry development and ripening and sugar content in the juice of harvested grapes $\left[\mathrm{kg} \cdot 100 \mathrm{~kg}^{-1}\right]$ in the studied period of 1990-2014. The PDSI negative value represents prevailing drought. Correlations for a) Riesling, b) Welschriesling, c) Grüner Veltliner, d) Müller Thurgau, e) Muscat Ottonel Weiss, f) Pinot Gris.

sugar content and for high yields, it depresses the berry sugar content [Trégoat et al., 2002]. The strength of the relationship between the PDSI and sugar content in the berries of the observed cultivars, was mostly weak to medium. The $\mathrm{R}^{2}$ value ranged from 0.103 (Muscat Ottonel Weiss) to 0.284 (Grüner Veltliner). There was no regularity in strength of correlation related to the cultivars grouped according to the earliness, though correlation was slightly weaker in the early cultivars compared to the late ones.

In all the observed cultivars, a positive correlation between the value of PDSI and acid content in berries was found (Fig. 2 a-f) which means that the dry conditions in the period of berry development and ripening caused a lower content of acids in grape berries. High temperatures causing high demand for water and enhancing drought 

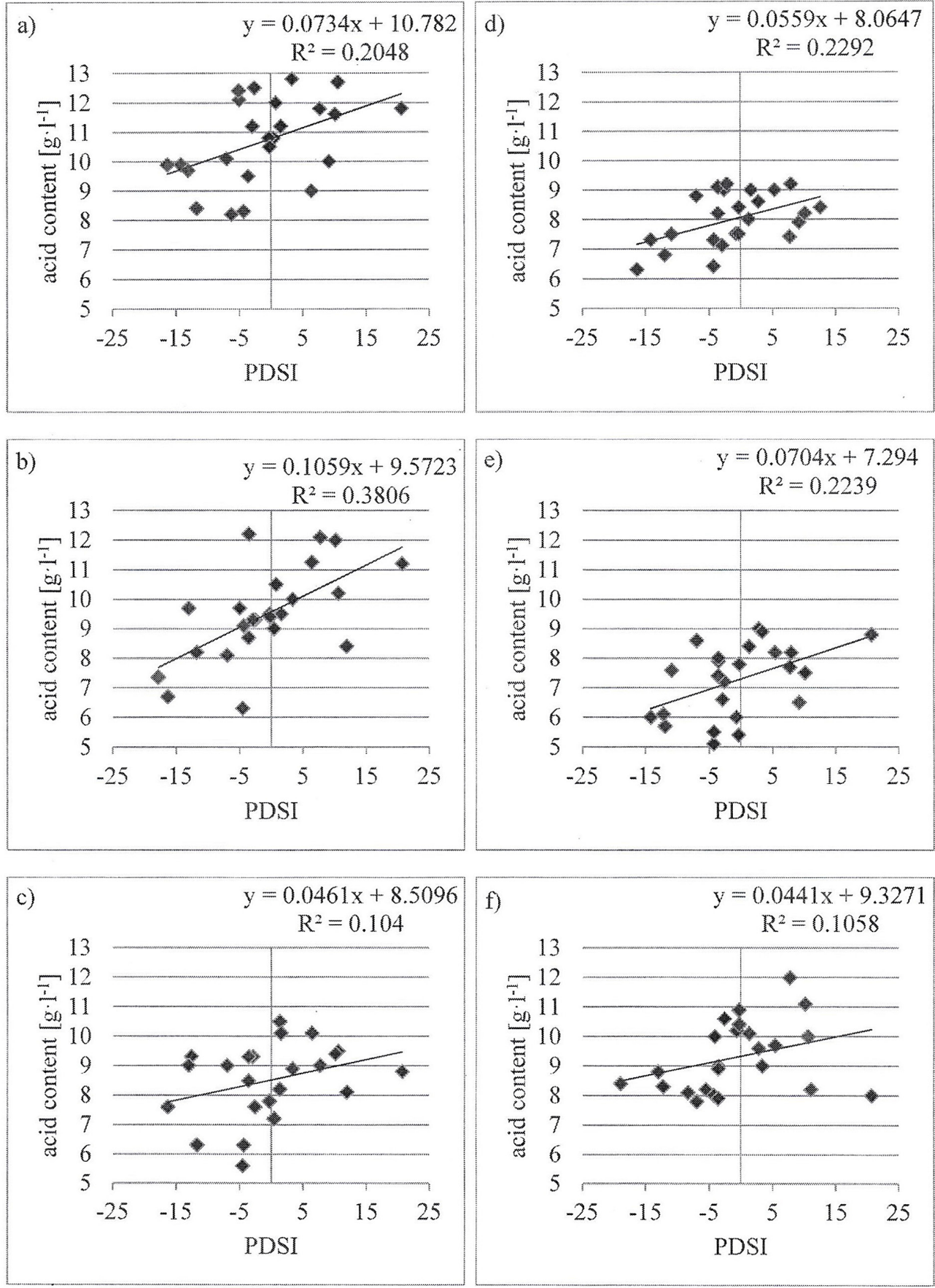

Figure 2. Correlation between PDSI in the period of grape berry development and ripening and acid content in the juice of harvested grapes $\left[\mathrm{g} \cdot \mathrm{l}^{-1}\right]$ in the studied period of 1990-2014. The PDSI negative value represents prevailing drought. Correlations for a) Riesling, b) Welschriesling, c) Grüner Veltliner, d) Müller Thurgau,

e) Muscat Ottonel Weiss, f) Pinot Gris

manifestation result in earlier ripening under high temperatures. The produced grapes then tend to contain high sugar levels, low concentration in organic acids [Sadra and Moran, 2012].

The experiments performed in Sardinia showed almost twice as high malic acid content in the fully irrigated berries compared to the berries from water deficit conditions, though different water supply did not present significant differences in the titrable acidity [Oliveira et al., 2013]. Vaz et al. [2016] comparedthe effect of four irrigation regimes with 2 cultivars in Portugal and observed the highest titrable acidity under the non-irrigated conditions. The strength of relationship between the PDSI and acid content in our observations was weak to medium, the highest in Welschriesling $\left(\mathrm{R}^{2}=0.3806\right)$. The weakest relationship between these variables was found 
in Grüner Veltliner $\left(\mathrm{R}^{2}=0.104\right)$ and Pinot Gris $\left(\mathrm{R}^{2}=0.1058\right)$. Similarly to the correlation between PDSI and sugar content, no regularity was found in the strength of correlation between PDSI and acid content related to cultivars grouped according to the earliness; however, the differences between late cultivars were greater. The difference between the mean $\mathrm{R}^{2}$ values for the relation of PDSI and the sugar content, as well as PDSI and the acid content was negligible, 0.187 and 0.208 respectively.

\section{CONCLUSION}

1. Within the observed period of 1990-2014, the years with drought during the period of grape berry development and ripening (BBCH 69 $89)$ were prevailing in the region of the experiment (South of Central Slovakia).

2. The drought which occured during the grape berry development and ripening resulted in a higher sugar content in berries.

3. The drought which occured during the grape berry development and ripening resulted in a lower content of acids in grape berries.

4. The strength of correlation between the drought severity as well as the sugar and acid contents in grape berries was weak to medium, the effect of drought on the observed quality parameters was ambiguous which confirms the complexity of the relation between the environmental conditions and the quality of grape.

5. Regarding the receptivity of grape quality to drought and continuing climate change thorough the approach to cultivar selection taking into account its vitality and ability to preserve satisfactory acid content is of increasing importance.

\section{Acknowledgements}

This paper was made with support of grant project VEGA 1/0767/17:Response of ecosystem services of grape growing country to climate change regional impact - change of functions to adaptation potential.

\section{REFERENCES}

1. Anonym. 2004. European Environment Agency (EEA) Impacts of Europe's changing climate.
An indicator-based assessment. Office for Official Publications of the European Communities, Luxembourg.

2. Balajka J., Lapin M., Mind'áš j., Št'astný P., Thalmeinerová D. 2005. The Fourth National Communication of the Slovak Republic on Climate Change, Ministry of the Environment of the Slovak Republic, Slovak Hydrometeorological Institute, Bratislava.

3. Battaglini A., Barbeau G., Bindi M., Badeck F.W. 2009. European winegrowers' perceptions of climate change impact and options for adaptation. Reg. Environ. Change 9 (2), 61-73.

4. Bock A., Sparks T., Estrella N., Menzel A. 2011. Changes in the phenology and composition of wine from Franconia Germany. Clim. Res. 50 (1), 69-81.

5. Chaves M.M., Santos T., Souza C.R., Ortuño M.F., Rodrigues M.L., Lopes C., Maroco J., Pereira J.S. 2007. Deficit irrigation in grapevine improves water-use efficiency while controlling vigour and production quality. Annals of Applied Biology 150 (2), 237-252.

6. Chuine I., Yiou P., Viovy N., Seguin B., Daux V., Le Roy Ladurie E. 2004. Historical phenology: grape ripening as a past climate indicator. Nature 432 (7015), 289-290.

7. Costa J.M., Ortuño M.F., Chaves M.M. 2007. Deficit irrigation as strategy to save water: physiology and potential application to horticulture. J. Integr. Plant Biol. 49, 1421-1434.

8. Dalla Marta A., Grifoni D., Mancini M., Storchi P., Zipoli G., Orlandini S. 2010. Analysis of the relationships between climate variability and grapevine phenology in the Nobile di Montepulciano wine production area. J. Agric. Sci. 148 (6), 657-666.

9. Daux V., Garcia de Cortazar-Atauri I., Yiou P., Chuine I., Garnier E., Le Roy Ladurie E., Moestre O., Tardaqila J. 2012. An open-database of grape harvest dates for climate research: data description and quality assessment. Climate Of the Past 8, 1403-1418.

10. Edwards E.J., Clingeleffer P.R. 2013 Interseasonal effects of regulated deficit irrigation on growth, yield, water use, berry composition and wine attributes of Cabernet Sauvignon grapevines. Australian Journal of Grape and Wine Research 19 (2), 261-276.

11. Escalona J.M., Flexas J., Medrano H. 1999. Stomatal and non-stomatal limitations of photosynthesis under water stress in field- grown grapevines. Aust. J. Plant Phys. 26, 421-433.

12. Faško P., Lapin M., Pecho J. 2008. 20-year Extraordinary Climatic Period in Slovakia. Meteorologický časopis, 11, 99-105.

13. Fendeková M., Gauster T., Labudová L., Vrabliková D., Danáčová Z., Fendek m., Pekárová P. 2018.Analysing 21 st century meteorological and hydrological drought events in Slovakia. J. Hydrol. Hydromech., 66 (4), 393-403. 
14. IPCC, 2013. Climate Change 2013: The Physical Science Basis. Contribution of Working Group I to the Fifth Assessment Report of the Intergovernmental Panel on Climate Change [Stocker T.F., Qin D., Plattner G.-K. , Tignor M., Allen S.K., Boschung J., Nauels A., Xia Y., Bex V., Midgley P.M.(eds.)]. Cambridge University Press, Cambridge, United Kingdom and New York, NY, USA.

15. Intrigliolo D.S., Pérez D., Risco D., Yeves A., Castel J.R. 2012 Yield components and grape composition responses to seasonal water deficits in Tempranillo grapevines. Irrigation Science 30 (5), 339-349.

16. Jones G.V., White M.A., Cooper O.R., Storchmann K. 2005 Climate change and global wine quality. Clim Change 73(3),319-343.

17. Keller M. 2010. Managing grapevines to optimise fruit development in a challenging environment: a climate change primer for viticulturists. Australian Journal of Grape and Wine Research 16, 56-59.

18. Labudová L., Faško P., Ivaňáková G. 2015. Changes in climate and changing climate regions. Moravian Geographical Reports 23 (3), 71-82.

19. Magalhães N. 2008. Viticulture treaty; The vine, the vineyard and the terroir (in Portuguese). Chaves Ferreira, Lisboa, Portugal.

20. Makra L., Vitányi B., Gál A., Mika J., Matyasovszky I., Hirsch T. 2009. Wine quantity and quality variations in relation to climatic factors in the Tokaj (Hungary) winegrowing region. Am. J. Enol. Vitic. 60,312-321.

21. Mandelli F., Tonietto J., Hasenack H., Weber E. 2005.Climatic zoning for the production of quality grape wines" heliothermic index for the state Rio Grande do Sul (in Portuguese) Proceeding of Congresso Brasileiro de Agrometeorologia, Campinas, 14.

22. Možný M., Brázdil R., Dobrovolný P., Trnka M., Potopová V., Hlavinka P., Bartošová L., Zahradníček P., Štěpánek P., Žalud Z. 2016. Drought reconstruction based on grape harvest dates for the Czech Lands, 1499-2012. Climate Research, 70,119-132.

23. Oliveira A.F., Mameli M.G., Pau L., Satta D., Nieddu D. 2013. Deficit Irrigation Strategies in Vitis vinifera L. cv. Cannonau under Mediterranean Climate. Part I - Physiological Responses, Growth, Yield and Berry Composition. S. Afr. J. Enol. Vitic. 34 (2), 170-183.

24. Palmer W. C. 1965. Meteorological Drought. U.S. Department of Commerce Weather Bureau, Research Paper No. 45, 58.

25. Parker A.k., CortÁzar-Atauri I.G. DE, van Leeuwen C., Chuine I. 2011. General phenological model to characterise the timing of flowering and veraison of Vitis vinifera L. Aust. J. Grape Wine Res., 17,206-216.

26. Poláček Š, Poláček M.2009. Viticulture and winemaking - brief history and present status (in Slovak). Viticulture - Viniculture fórum Skalica 2009, 25
-26.2. 2009, zborník, Slovenská pol'nohospodárska univerzita, ISBN 978-80-552-0308-9.

27. Romero P., Fernández J.I., Martinez-Cutillas A. 2012. Physiological thresholds for efficient regulated deficit-irrigation management in winegrapes grown under semiarid conditions. Soil-Plant-Water Relationships and Berry Composition. Acta Horticulturae, 931 (931), 171-178.

28. Sadras V., Moran M. 2012. Elevated temperature decouples anthocyanins and sugars in berries of Shiraz and Cabernet Franc. Aust. J. Grape Wine Res.18, 115-122.

29. Santos T.P., Lopes C.M., Rodrigues, L. M., de Souza C.R., Ricardo-da-Silva J.M., Maroco J.P., Pereira J.S., Chaves M. M. 2007. Effects of deficit irrigation strategies on cluster microclimate for improving fruit composition of Moscatel field-grown grapevines. Scientia Horticulturae. 112 (3), 321-330.

30. Storchi P., Costantini E. A. C., Bucelli P. 2005. The influence of climate and soil on viticultural and enological parameters of "Sangiovese" grapevines under non-irrigated conditions. Acta Hortic. 689, 333-340.

31. Šiška B., Takáč J. 2009. Drought Analyse of Agricultural Regions as Influenced by Climatic Conditions in the Slovak Republic. Időjárás: Quarterly Journal of the Hungarian Meteorological Service, 113 (1-2), 135-143.

32. Trégoat O., Van Leeuwen C., Choné X., Gaudillère J.-P. 2002 Ètude du régime hydrique et de la nutrition azotée de la vigne par des indicateurs physiologiques. Influence sur le comportement de la vigne et la maturation du raisin. J. Int. Sci. Vigne Vin, 36 (3), 133-142.

33. Van Leeuwen C., Trégoat O., Choné X., Gaudillère J.P., Pernet D. 2007. Different environmental conditions, different results: the role of controlled environmental stress on grape quality potential and the way to monitor it. Proceedings of the thirteenth Australian Wine Industry Technical Conference, Adelaide, South Australia.

34. Van Leeuwen C., Trégoat O., Choné X., Bois B., Pernet, D., Gaudillére J.P. 2009.Vine water status is a key factor in grape ripening and vintage qualityfor red Bordeaux wine. How can it be assessed for vineyard management purposes?Journal International des Sciences de la Vigne et du Vin, 43 (3), 121-134.

35. VazM., Coelho R., Rato A., Samara-Lima R., Silva L.L., Campostrini E., Mota J.B. 2016. Adaptive strategies of two Mediterranean grapevinesvarieties (Aragonez syn. Tempranillo and Trincadeira) facedrought: physiological and structural responses. Theor. Exp. Plant Physol., 28, 205-220.

36. Wenter A., Zanotelli D., Montagnani L., Tagliavini M., Andreotti C. 2018. Effect of different timings and intensities of water stress on yield and berry composition of grapevine (cv. Sauvignon blanc) in a mountain environment. Scientia Horticulturae, 236, 137-145 